\title{
Dust Acid Uptake Analysis during Long-Lasting Dust and Pollution Episodes over East Asia Based on Synergetic Observation and Chemical Transport Model
}

\author{
Itsushi Uno ${ }^{1}$, Keiya Yumimoto ${ }^{1}$, Kazuo Osada ${ }^{2}$, Zhe Wang ${ }^{1,3}$, Xiaole Pan ${ }^{3}$, \\ Syuichi Itahashi ${ }^{4}$, and Shigekazu Yamamoto ${ }^{5}$ \\ ${ }^{1}$ Research Institute for Applied Mechanics, Kyushu University, Kasuga, Fukuoka, Japan \\ ${ }^{2}$ Graduate School of Environmental Studies, Nagoya University, Nagoya, Japan \\ ${ }^{3}$ Institute of Atmospheric Physics, CAS, Beijing, China \\ ${ }^{4}$ Central Research Institute of Electric Power Industry, Abiko, Chiba, Japan \\ ${ }^{5}$ Fukuoka Institute of Health and Environmental Sciences, Dazaifu, Fukuoka, Japan
}

\begin{abstract}
Two heavy dust storms that occurred between 24-26 May 2014 in Mongolia and Inner Mongolia, China were responsible for long-lasting dust episodes observed from 26 May to 2 June 2014 in Fukuoka, Japan. During this period, dust and anthropogenic pollutants were transported simultaneously to Fukuoka and Korea and remained there for almost 8 days. We successfully observed fine and coarse aerosol time variations (1-hour intervals) in Fukuoka. The GEOS-Chem chemical transport model, which includes dust-acid uptake processes, successfully reproduced the aerosol variations and explained the Asian-scale dust-pollutant transport and transformation processes. Model sensitivity analyses with and without dust-acid uptake processes showed that the formation of dust-nitrate occurred over the Yellow Sea and East China Sea before arriving in Japan. The model sensitivity analysis showed that less than $5 \%$ of the coarse dust-nitrate originated from NOx emissions from Japan, and large amounts of dustnitrate originated outside of Japan.

(Citation: Uno, I., K. Yumimoto, K. Osada, Z. Wang, X. Pan, S. Itahashi, and S. Yamamoto, 2017: Dust acid uptake analysis during long-lasting dust and pollution episodes over East Asia based on synergetic observation and chemical transport model. SOLA, 13, 109-113, doi:10.2151/sola.2017-020.)
\end{abstract}

\section{Introduction}

Asian dust plays a major role in the deterioration of the atmospheric environment, impacts surface ecosystems, modulates the atmospheric radiation balance, and causes significant human health problems (e.g., Mahowald et al. 2010; Perez et al. 2008). Detailed case studies are needed to elucidate physical and chemical variations of dust events.

The working group I (WG-I) of the Tripartite Environment Ministers Meeting (TEMM; http://www.temm.org) of China, Japan, and the Republic of Korea has been studying typical heavy dust events, using observational and numerical approaches and sharing particulate matter (PM) measurements obtained from each country. Within the recent framework of TEMM WG-I, a high dust concentration episode that occurred between 22 May and 4 June 2014 was selected as a case study of a dust and sand storm event. During this period, two dust storms occurred on 24 May (Dust A) and 26 May (Dust B) over dust source regions, and long-lasting dust and air pollution were observed in East Asia, including Seoul, Korea and Fukuoka, Japan, for more than a week. These long-lasting dust and pollution episodes provided an excellent opportunity for studying the mixing process of dust and pollution, and the formation of well-aged polluted dust (e.g., dust-nitrate) because the inclusion of dust-nitrate is important to

Corresponding author: Itsushi Uno, Research Institute for Applied Mechanics, Kyushu University, Kasuga, Fukuoka 816-8580, Japan. E-mail: uno@riam.kyushu-u.ac.jp. (C2017, the Meteorological Society of Japan. the analysis of anthropogenic $\mathrm{NO}_{3}{ }^{-}$long-range transport and its potential impact on both ocean and land ecosystems. The basic dust modeling results for this dust event was already reported by Yumimoto et al. (2017). In this paper, we investigate in detail the behaviors of dust and anthropogenic pollutants, and the role of the heterogeneous formation of dust-nitrate (e.g., $\left.\mathrm{Ca}\left(\mathrm{NO}_{3}\right)_{2}\right)$ as a "polluted dust" based on intensive surface observations and chemical transport modeling.

\section{Methods}

Our aerosol observation methods [using an aerosol chemical speciation analyzer (ACSA) and a polarization optical particle counter (POPC)] and details of the chemical transport model (CTM) configuration (GEOS-Chem v9-02; Bey et al. 2001; Fiarlie et al. 2007, 2010) have been reported previously (Uno et al. 2017a; Yumimoto et al. 2017; Pan et al. 2015). A global GEOS-Chem simulation $\left(2^{\circ} \times 2.5^{\circ}\right.$ resolution $)$ was conducted from January 2013 to the end of June 2014, and an Asian nest simulation $\left(0.5^{\circ}\right.$ $\times 0.667^{\circ}$ resolution) using boundary conditions from the global simulation began in April 2014. Our previous report (Uno et al. 2016) analyzed the same episode; we improved the dust modeling performance by using a new inversion method (Yumimoto et al. 2017), modifying dry deposition of nitrate and nitric acid (Itahashi et al. 2017), and included detailed chemical budget analysis of acid uptake along the dust trajectory from China to Japan. We also analyzed aerosol acidity with ACSA. Aerosol acidity (fine and coarse $\Delta \mathrm{H}^{+}$) refers to the difference in the solution of particles relative to the extracting liquid, and is determined using a $\mathrm{pH}$ indicator absorption photometric method. The basic equation is $\mathrm{pH}_{\text {solution }}=-\log \left[\Delta \mathrm{H}^{+} \times 10^{-6}+10^{-4.6}\right]$. Here, $\mathrm{pH}_{\text {solution }}$ is the $\mathrm{pH}$ value of the aqueous extracts of the aerosol samples, and the extract solvent had a $\mathrm{pH}$ of 4.6 . Therefore, $\Delta \mathrm{H}^{+}$serves as a good indicator of aerosol pH (Kimoto et al. 2013).

In the modeling analysis, we performed a control experiment (CNTL), several sensitivity analyses with and without dust acid uptake processes, an experiment based on a $20 \%$ reduction of all Japanese emissions, and a volcanic $\mathrm{SO}_{2}$ zero-emissions experiment. Hereafter, we denote modeled "ammonium" nitrate (i.e., $\mathrm{NH}_{4} \mathrm{NO}_{3}$ ) as "A- $\mathrm{NO}_{3}^{-}$", dust-nitrate as " $\mathrm{D}-\mathrm{NO}_{3}^{-}$", and their sum simply as " $\mathrm{NO}_{3}$ "".

\section{Results and discussion}

\subsection{Dust/pollutant transport and time variations at Fukuoka and Seoul}

Figure 1 shows the $\mathrm{SO}_{2}$ and dust emissions (total amount of dust emissions for all dust bins simulated by GEOS-Chem). The two blue lines in the figure indicate the Hybrid Single-Particle Lagrangian Integrated Trajectory model (HYSPLIT) back-trajectories, starting from the time when a high concentration of dust was first observed in Fukuoka, Japan.

Figure 2 shows the time variations of (a) concentration of fine 


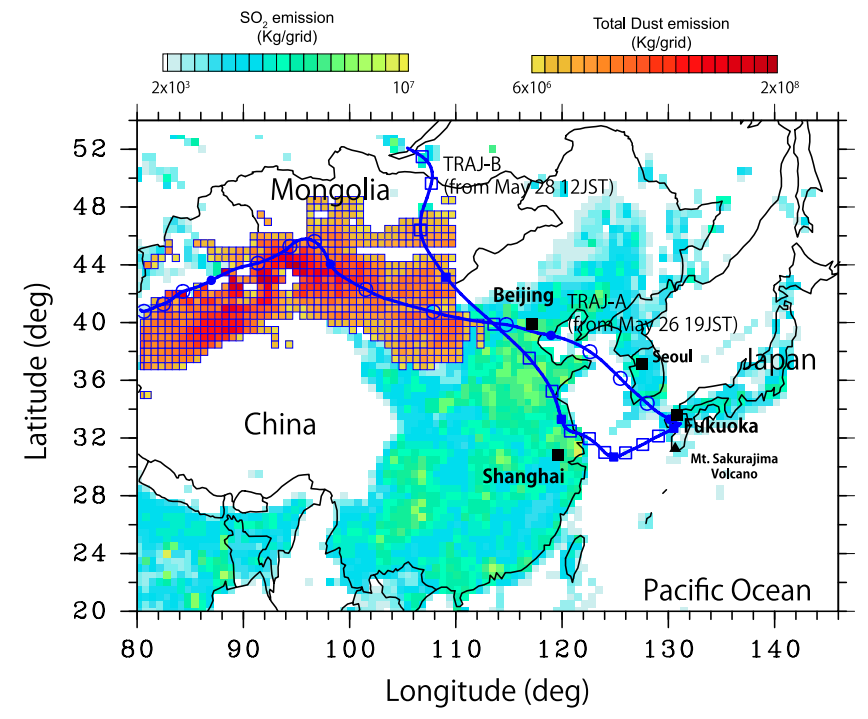

Fig. 1. $\mathrm{SO}_{2}$ emissions in May and modeled total dust emissions from 20 May to 5 June 2014 (colored logarithmic scale). Lines with symbols (6-h intervals) show the Hybrid Single-Particle Lagrangian Integrated Trajectory model (HYSPLIT) backward trajectory from 26 May, 19JST (TRAJ-A) and 28 May, 12JST (TRAJ-B) passing through the middle of Kyushu, Japan $(\mathrm{z}=500 \mathrm{~m})$.
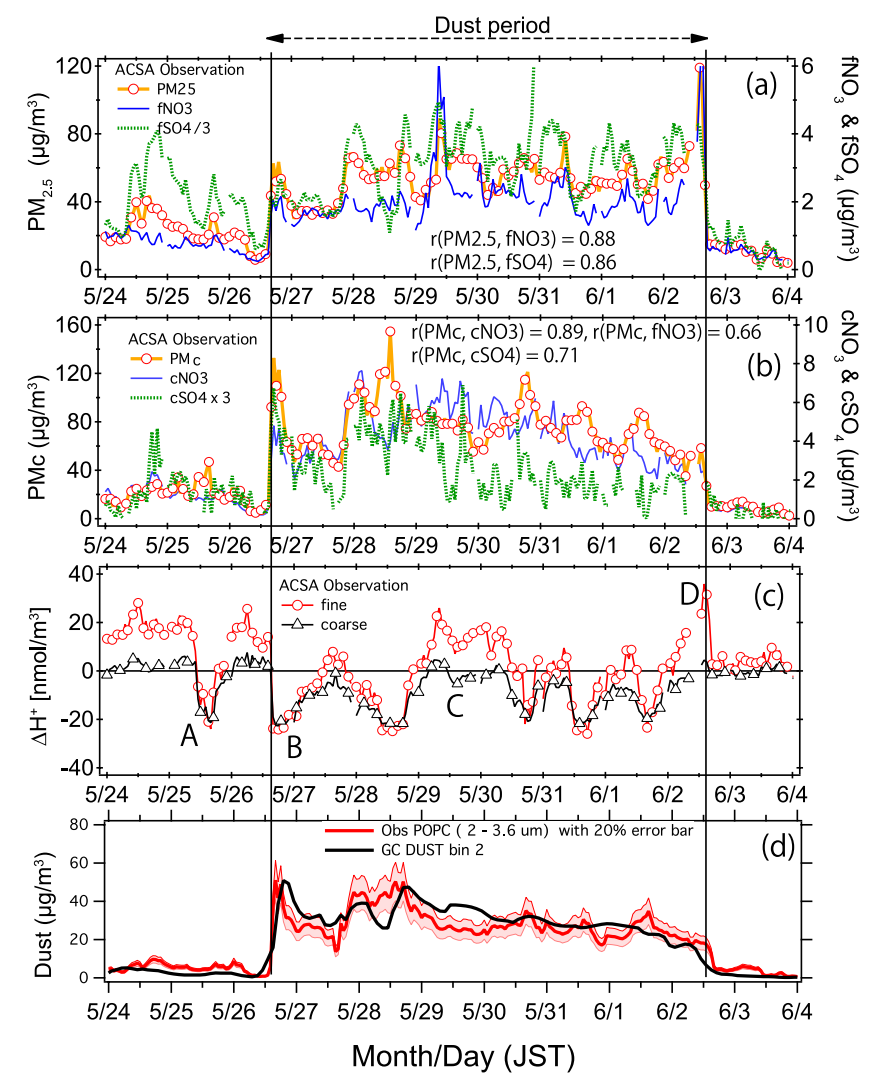

Fig. 2. Time series plots of (a) observed fine particulate matter $\left(\mathrm{PM}_{2.5}\right)$, fine $\mathrm{NO}_{3}^{-}\left(\mathrm{fNO}_{3}{ }^{-}\right)$, and fine $\mathrm{SO}_{4}{ }^{2-}\left(\mathrm{fSO}_{4}{ }^{2-}\right)$ by aerosol chemical speciation analyses (ACSA), (b) observed coarse particulate matter $\left(\mathrm{PM}_{\mathrm{c}}\right)$, coarse $\mathrm{NO}_{3}^{-}\left(\mathrm{cNO}_{3}{ }^{-}\right)$, and coarse $\mathrm{SO}_{4}{ }^{2-}\left(\mathrm{cSO}_{4}{ }^{2-}\right)$ by ACSA, (c) observed $\Delta \mathrm{H}^{+}$of aerosol by ACSA, (d) observed polarization optical particle counter (POPC) concentrations (symbol) for particles of diameter 2.0-3.6 $\mu \mathrm{m}$, and GEOSChem dust bin 2 (black line, corresponding to POPC diameter range). Symbols A - D in (c) are the time slices used in Supplemental Fig. 2. mode (particulate diameter $<2.5 \mu \mathrm{m}$ ) of particulate matter $\left(\mathrm{PM}_{2.5}\right)$, $\mathrm{NO}_{3}{ }^{-}$and $\mathrm{SO}_{4}{ }^{2-}$; (b) concentration of coarse mode (particulate diameter 2.5-10 $\mu \mathrm{m})$ of particulate matter $\left(\mathrm{PM}_{\mathrm{c}}\right), \mathrm{NO}_{3}{ }^{-}$and $\mathrm{SO}_{4}{ }^{2-}$; (c) fine and coarse aerosol acidity $\left(\Delta \mathrm{H}^{+}\right)$measured by ACSA; and (d) GEOS-Chem dust and POPC particle volume concentration in the 2.0-3.6 $\mu \mathrm{m}$ size range (corresponding to GEOS Chem dust bin 2).

Figure 3 shows the observed and modeled time variations of $\mathrm{PM}_{2.5}$ and $\mathrm{PM}_{\mathrm{c}}$ concentrations at Fukuoka and Seoul.

During the observation period, two large dust storms occurred in Mongolia and Inner Mongolia, China. The first dust storm occurred on 24 May 2014 (Dust A) and the second one mainly on 26 May 2014 (Dust B). Supplemental Fig. 1 shows the simulated horizontal distribution of daily dust and anthropogenic $\mathrm{SO}_{4}{ }^{2-}$ concentrations between 24 May and 2 June 2014 (time at 0:00 Coordinated Universal Time (0UTC) $=$ 9:00 Japan Standard Time (9JST) at the model's first vertical level, $z=65 \mathrm{~m}$ ).

The daily dust distributions clearly showed two sequential dust onsets (A and B) in Korea and Japan. Dust A arrived in Shanghai, Seoul, and Fukuoka on 26 May 2014. A portion of dust A remained in southern China for a protracted period. Dust B was transported to Inner Mongolia, Shanxi, south of Hebei province, the base of Shandong Peninsula, arrived in Fukuoka on 28 May 2014 and remained in Fukuoka until 2 June. The area covered by Dust A was wider than that covered by Dust B. From 30 May to 1 June 2014, large amounts of dust (mainly originating from Dust A) and pollutants were transported from southern China to the Seoul region, due to clockwise air circulation at the backside of a high-pressure system, which brought aged pollutants to Korea. This indicates that the Seoul region experienced dust pollution twice by direct transport and the other dust detoured over the Shanghai region from the Dust A event.

We found that the modeled $\mathrm{PM}_{25}$ and $\mathrm{PM}_{\mathrm{c}}$ were in good agreement with observations from both Fukuoka and Seoul. The $\mathrm{PM}_{2.5}$
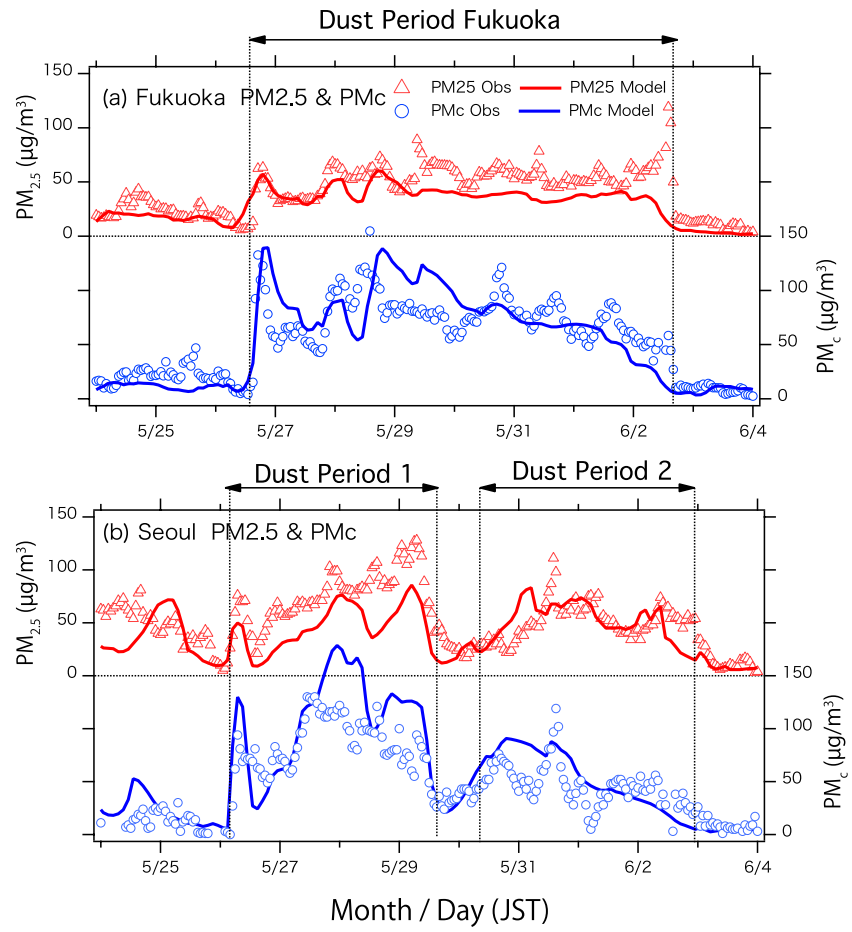

Fig. 3. Time series plots of (a) observed $\mathrm{PM}_{25}$ (red triangles) and $\mathrm{PM}_{\mathrm{c}}$ (blue circles) and modeled $\mathrm{PM}_{2.5}$ (red line) and $\mathrm{PM}_{\mathrm{c}}$ (blue line) in Fukuoka, Japan; and (b) observed $\mathrm{PM}_{2.5}$ (red triangles) and $\mathrm{PM}_{\mathrm{c}}$ (blue circles) and modeled $\mathrm{PM}_{2.5}$ (red line) and $\mathrm{PM}_{\mathrm{c}}$ (blue line) in Seoul, Korea. For Seoul, $\mathrm{PM}_{2.5}$ data from the National Institute of Environmental Research, Korea, and $\mathrm{PM}_{10}$ data from the Korea Meteorological Agency. $\mathrm{PM}_{\mathrm{c}}$ calculated as $\mathrm{PM}_{10}-\mathrm{PM}_{2.5}$. 
variation in Fukuoka showed a single long-term high concentration, while in Seoul the concentration had two peaks, which the model reproduced quite well (although it slightly underestimated the first dust period). The trajectory analysis shown in Supplementary Fig. 1 clearly explains these two peak variations for Seoul (direct and detour transport). The high $\mathrm{PM}_{2.5}$ concentration on 2 June 2014 at Fukuoka came from domestic pollution (mainly biomass burning which was not explicitly included in CTM) at Kyushu Island, as reported by Uno et al. (2016).

POPC data is a good indicator of dust, and we saw a high correlation between $\mathrm{PM}_{\mathrm{c}}$ and POPC. During the dust period, $\mathrm{PM}_{\mathrm{c}}$ was highly correlated with coarse $\mathrm{NO}_{3}^{-}\left(\mathrm{cNO}_{3}^{-} ; \mathrm{r}=0.89\right)$. A high correlation was also found for fine $\mathrm{NO}_{3}{ }^{-}\left(\mathrm{fNO}_{3}{ }^{-}\right)(\mathrm{r}=0.66)$, indicating that the influence of the dust also extended to $\mathrm{fNO}_{3}{ }^{-}$. Coarse $\mathrm{SO}_{4}{ }^{2-}$ $\left(\mathrm{CSO}_{4}{ }^{2-}\right)$ had a low concentration, but was still highly correlated with $\mathrm{PM}_{\mathrm{c}}(\mathrm{r}=0.71)$.

$\Delta \mathrm{H}^{+}$of coarse aerosol $\left(\mathrm{c} \Delta \mathrm{H}^{+}\right)$was inversely correlated with POPC. We observed that when $\mathrm{PM}_{\mathrm{c}}$ had a high value (e.g., $\mathrm{PM}_{\mathrm{c}}>$ $\left.100 \mu \mathrm{g} / \mathrm{m}^{3}\right)$, the $\mathrm{c} \Delta \mathrm{H}^{+}$was negative. This indicated that the dust had a high alkalinity derived from the $\mathrm{CaCO}_{3}$, and effectively neutralized acidic aerosols containing sulfate and nitrate. On the other hand, $\Delta \mathrm{H}^{+}$of fine aerosol $\left(\mathrm{f} \Delta \mathrm{H}^{+}\right)>20 \mathrm{nmol} / \mathrm{m}^{3}$ in the " $\mathrm{C}$ " and " $\mathrm{D}$ " periods was due to co-existing anthropogenic fine acid aerosols during the dust period, but this enhancement was not seen for $\mathrm{c} \Delta \mathrm{H}^{+}$. Particle volume concentration as a function of the particle diameter and deporalization ratio (DR) (DR-Dp-Volume plot) is a good metric for confirming the mixing of aerosol particles, as shown by Pan et al. (2015) and Uno et al. (2017a). Supplemental Fig. 2 shows the results for the time slices A, B, C, and D, and explains our observations and modeled results. Note that $\Delta \mathrm{H}^{+}<0$ for time slice A came from sea salt, as discussed in Supplement 2.

\subsection{Aerosol compositions in Fukuoka}

Figure 4 shows the time variations of observed and modeled (a) fine $\mathrm{SO}_{4}{ }^{2-}$ (CNTL and Volcanic $\mathrm{SO}_{2} \mathrm{OFF}$ results) and wind vectors at Fukuoka, (b) fine $\mathrm{NO}_{3}^{-}$and $\mathrm{D}-\mathrm{NO}_{3}^{-}$, and (c) coarse $\mathrm{NO}_{3}{ }^{-}$. Figure $4 \mathrm{c}$ also includes the modeled $\mathrm{D}-\mathrm{NO}_{3}{ }^{-}$and sea salt $\mathrm{NO}_{3}^{-}$. Modeled $\mathrm{SO}_{4}{ }^{2-}$ showed the same magnitude as ACSA observations, but underestimated during the period of 29 May and 2 June. Model sensitivity results from turning off all of volcanic $\mathrm{SO}_{2}$ emissions indicated that $20 \%$ of the total $\mathrm{SO}_{4}{ }^{2-}$ came from volcano $\mathrm{SO}_{2}$ emissions (more than $65 \%$ of them is coming from Mt. Sakurajima; see Fig. 1 for the location of Sakurajima, and Fig. 4a for wind fields). Precise prediction of day-to-day variations in volcanic $\mathrm{SO}_{2}$ emissions is difficult, and this is one of the reasons for the underestimation.

Modeled fine $\mathrm{D}-\mathrm{NO}_{3}{ }^{-}$showed the good baseline variation of observed fine $\mathrm{NO}_{3}^{-}$, and the variation between modeled fine $\mathrm{A}-\mathrm{NO}_{3}{ }^{-}+\mathrm{D}-\mathrm{NO}_{3}{ }^{-}$was within the observed range, but the $\mathrm{A}-\mathrm{NO}_{3}{ }^{-}$ fraction was sometimes over-predicted because of the model performance of the gas and particle equilibrium $\left(\mathrm{NH}_{4} \mathrm{NO}_{3} \Leftrightarrow\right.$ $\mathrm{HNO}_{3}+\mathrm{NH}_{3}$ ) issue as discussed in Itahashi et al. (2017). The $\mathrm{NO}_{3}{ }^{-}$fraction of Japanese domestic emissions was high on 29, 31 May, and 1-2 June 2014 (indicated as "J" in Fig. 4b), but no peak was observed for $\mathrm{CNO}_{3}^{-}$(the contribution of Japanese emissions to coarse $\mathrm{D}-\mathrm{NO}_{3}{ }^{-}$was $5 \%$ ). Modeled results indicated that the contribution of $\mathrm{D}-\mathrm{NO}_{3}{ }^{-}$was higher than that of $\mathrm{A}-\mathrm{NO}_{3}{ }^{-}$(the ratio of fine $\mathrm{D}-\mathrm{NO}_{3}{ }^{-}$to fine $\mathrm{A}-\mathrm{NO}_{3}{ }^{-}$was approximately $2: 1$ ) and explained the time variation of the observed fine $\mathrm{NO}_{3}^{-}$(during the dust period, the basic time variation of fine $\mathrm{NO}_{3}{ }^{-}$was explained by fine D-NO3). The concentration of coarse $\mathrm{D}-\mathrm{NO}_{3}{ }^{-}$was approximately three times higher than that of fine $\mathrm{D}-\mathrm{NO}_{3}^{-}$, and the modeled results reproduced the observed coarse $\mathrm{NO}_{3}{ }^{-}$well. The contribution of sea salt $\mathrm{NO}_{3}{ }^{-}$was smaller than that of coarse $\mathrm{D}-\mathrm{NO}_{3}{ }^{-}$.

\subsection{Formation of dust-nitrate along the air mass trajectory}

Figure 5 shows (a) the simulated total dust and $\mathrm{RH}$; (b) $\mathrm{SO}_{2}$, $\mathrm{NH}_{3}$, fine $\mathrm{NH}_{4}^{+}$, and fine $\mathrm{SO}_{4}{ }^{2-}$; (c) fine $\mathrm{A}-\mathrm{NO}_{3}^{-}, \mathrm{HNO}_{3}$, and the sum of all $\mathrm{D}-\mathrm{NO}_{3}^{-}$; and (d) $\Delta \mathrm{HNO}_{3}=\mathrm{HNO}_{3}$ (without uptake) $\mathrm{HNO}_{3}$ (with uptake), along the HYSPLIT back-trajectory path (500-m level path) for the TRAJ-A, as shown in Fig. 1. In Fig. 5b
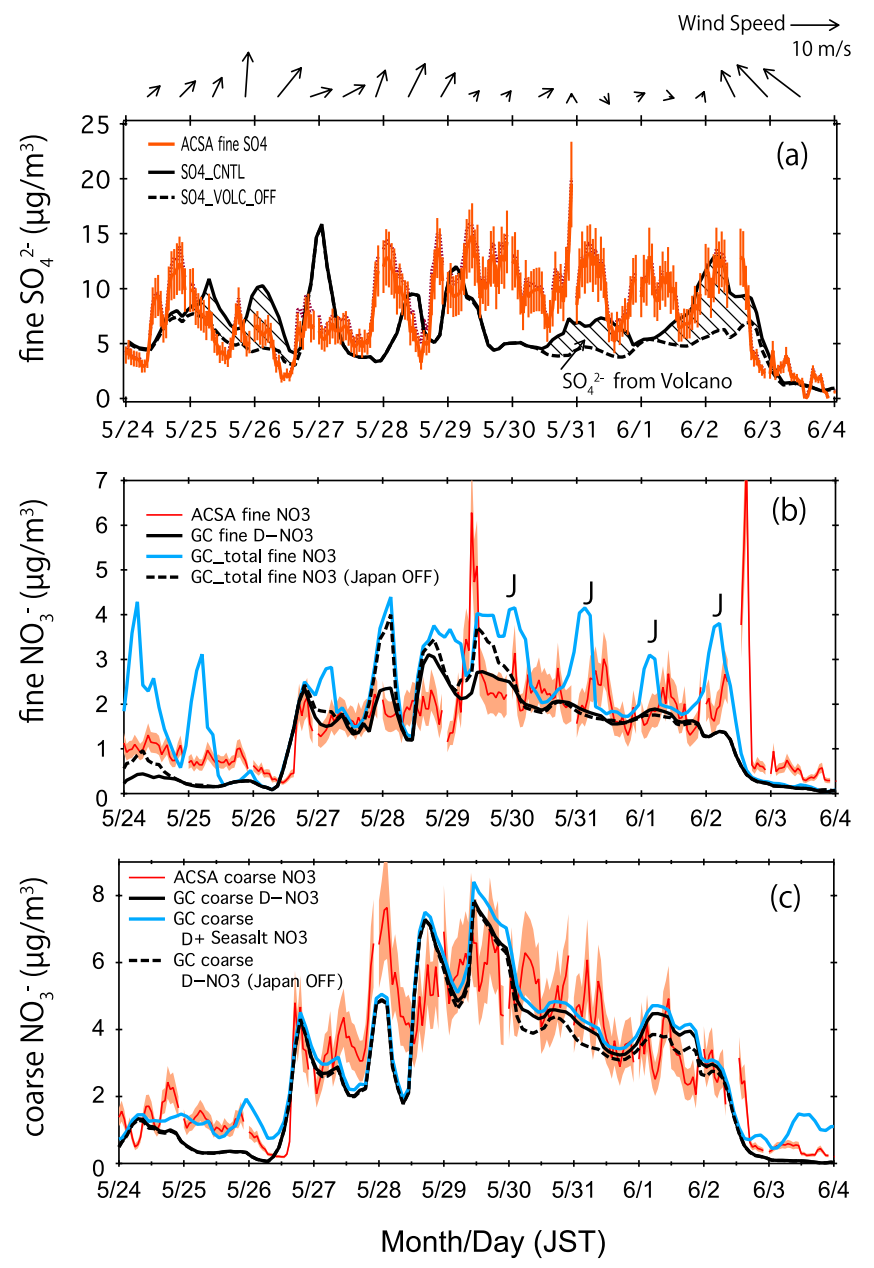

Fig. 4. Time series plots of observed and modeled (a) fine $\mathrm{SO}_{4}{ }^{2-}$ [black solid line for control experiment (CNTL) and dashed line for model without volcano emissions] and wind fields at Fukuoka; (b) fine $\mathrm{NO}_{3}^{-}$and $\mathrm{D}-\mathrm{NO}_{3}{ }^{-}$, and (c) coarse $\mathrm{NO}_{3}^{-}$and $\mathrm{D}-\mathrm{NO}_{3}^{-}$at Fukuoka. The black dashed line indicates the concentration without Japanese emissions modeled in a sensitivity experiment.

and $5 \mathrm{c}$, we also showed the sensitivity results without the dustacid uptake processes with dashed lines. In Fig. 5c, sea salt $\mathrm{NO}_{3}{ }^{-}$ was not included because of its low concentration.

Figure 5a shows the rapid decrease of dust concentration along the trajectory due to strong diffusion and deposition. Relative humidity over the landmass of China ranged from 20 to $40 \%$, but it increased rapidly, up to $80-95 \%$, when the air mass reached the ocean. Relative humidity decreased when the air mass passed over the Korean Peninsula.

In Fig. 5b, $\mathrm{SO}_{2}$ peaked over the Chinese landmass to the Bohai Sea and then decreased, and the $\mathrm{SO}_{4}{ }^{2-}$ level inversely increased due to the chemical conversion of $\mathrm{SO}_{2}$ to $\mathrm{SO}_{4}{ }^{2-}$. Similar changes were seen in $\mathrm{NH}_{3}$ and $\mathrm{NH}_{4}^{+}$. $\mathrm{NH}_{3}$ leveled out over Yantai, at the tip of the Shandong Peninsula.

Fine $\mathrm{A}-\mathrm{NO}_{3}{ }^{-}$concentrations peaked when the air mass left mainland China. After leaving mainland China and moving toward the Yellow Sea, the $\mathrm{NH}_{3}$ supply stopped and $\mathrm{A}-\mathrm{NO}_{3}{ }^{-}$(i.e., $\mathrm{NH}_{4} \mathrm{NO}_{3}$ ) was thermally decomposed into $\mathrm{HNO}_{3}$ and $\mathrm{NH}_{3}$, and $\mathrm{NH}_{3}$ was then used for the formation of $\mathrm{NH}_{4} \mathrm{HSO}_{4}$ and $\left(\mathrm{NH}_{4}\right)_{2} \mathrm{SO}_{4}$. There were no differences in fine $\mathrm{A}-\mathrm{NO}_{3}{ }^{-}$levels with and without dust-acid uptake processes, and fine $\mathrm{A}-\mathrm{NO}_{3}{ }^{-}$leveled out (similar to $\mathrm{NH}_{3}$ ). This indicated that $\mathrm{A}-\mathrm{NO}_{3}{ }^{-}$could not reach Japan under the meteorological conditions at the end of May, 2014 and only $\mathrm{D}-\mathrm{NO}_{3}^{-}$components arrived in Japan. This is consistent with the long-term analysis results from Uno et al. (2017b).

The variations in $\mathrm{HNO}_{3}$ and $\mathrm{D}-\mathrm{NO}_{3}{ }^{-}$shown in Fig. $5 \mathrm{c}$ and 

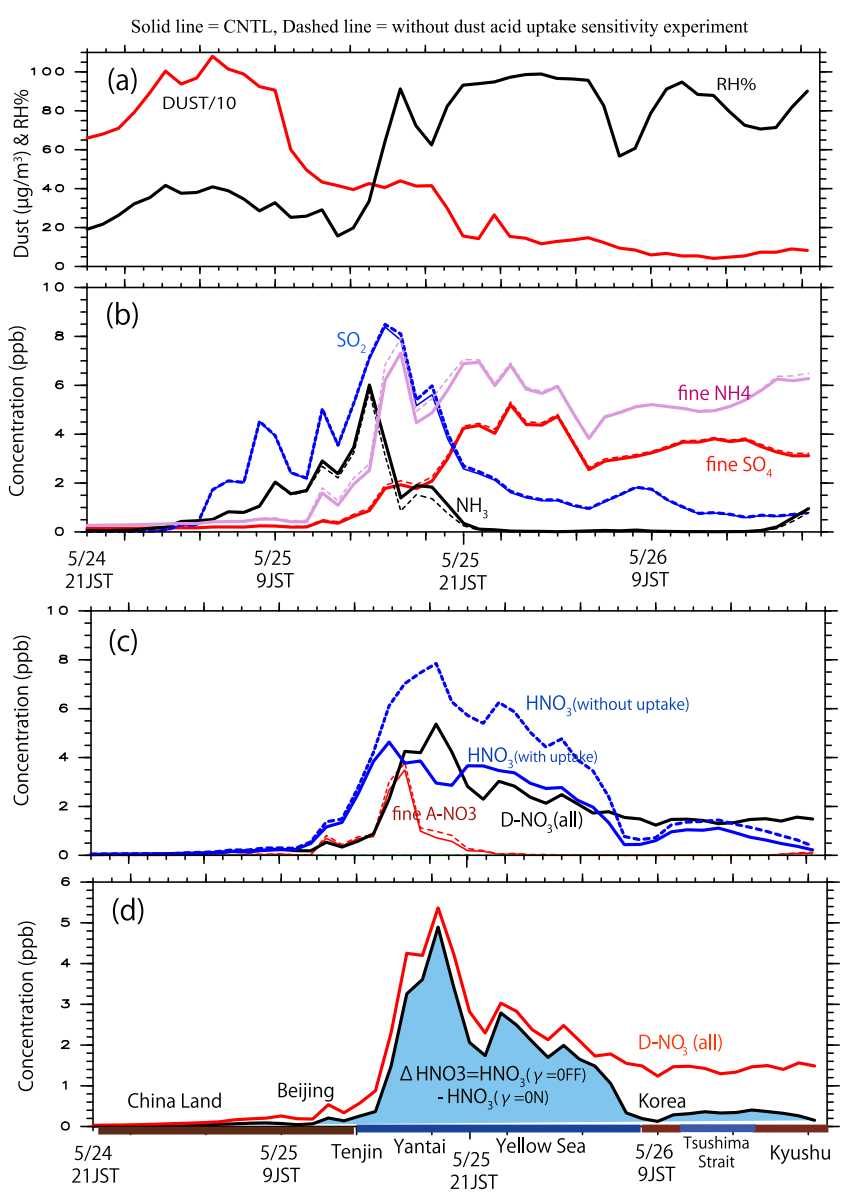

$5 \mathrm{~d}$ are important for understanding dust-acid uptake. The model results showed maximum $\Delta \mathrm{HNO}_{3}$ increases up to $5 \mathrm{ppb}$ over the Bohai and Yellow Seas, and this uptake led to rapid formation of $\mathrm{D}-\mathrm{NO}_{3}{ }^{-}$due to high $\mathrm{RH}$ and the additional $\mathrm{HNO}_{3}$ supply from A- $\mathrm{NO}_{3}{ }^{-}$decomposition.

Figure $5 \mathrm{~d}$ shows that $\mathrm{D}-\mathrm{NO}_{3}{ }^{-}>\Delta \mathrm{HNO}_{3}$ due to the differences in deposition velocity of gas and aerosols $\left(\mathrm{D}-\mathrm{NO}_{3}{ }^{-}\right.$has a longer life time and is important to long-range transport from China to Japan). We found a very similar variation for TRAJ-B in our analysis (data not shown).

\subsection{Period averaged dust-acid uptake analysis}

Figure 6 shows the period averaged fine (a) and coarse (b) D- $\mathrm{NO}_{3}{ }^{-}$concentrations, and fine (c) and coarse (d) dust concentrations and the ratio of $\mathrm{D}-\mathrm{NO}_{3}{ }^{-} /$dust concentration. From these figures, it is clear that $\mathrm{D}-\mathrm{NO}_{3}{ }^{-}$formation occurred over the Yellow Sea off the Korean coast and over the Sea of Japan. The peak coarse $\mathrm{D}-\mathrm{NO}_{3}{ }^{-}$concentration occurred over the Sea of Japan, because the dust-acid uptake velocity was slower than that of fine $\mathrm{D}-\mathrm{NO}_{3}{ }^{-}$(even though the peak concentration was 2.7 times higher). Supplemental Fig. 3 shows the average distribution of $\Delta \mathrm{HNO}_{3}$ at the model's first vertical level between 20 May and 4 June 2104. This shows clearly that $\mathrm{HNO}_{3}$ was absorbed mainly over the Bohai and Yellow Seas when the RH became higher.

These results confirmed that the dust-nitrate outflow from China to Japan was responsible for the long-range transport of $\mathrm{NO}_{3}{ }^{-}$and the uptake of anthropogenic $\mathrm{NO}_{x}$ and $\mathrm{HNO}_{3}$ into dust.

Fig. 5. (a) Simulated total dust, $\mathrm{RH}$; (b) $\mathrm{SO}_{2}, \mathrm{NH}_{3}$, fine $\mathrm{NH}_{4}^{+}$, fine $\mathrm{SO}_{4}^{-}$; (c) fine $\mathrm{A}-\mathrm{NO}_{3}^{-}, \mathrm{HNO}_{3}$, sum of all D-NO ${ }_{3}^{-}$; (d) $\triangle \mathrm{HNO}_{3}=\mathrm{HNO}_{3}$ (without uptake) $-\mathrm{HNO}_{3}$ (with uptake) along the HYSPLIT back-trajectory path for the TRAJ-A shown in Fig. 1. Solid and dashed lines in (b) and (c) indicate the model sensitivity experiments with and without the dust-acid uptake option, respectively.

(a) fine $\mathrm{D}-\mathrm{NO}_{3}$ -

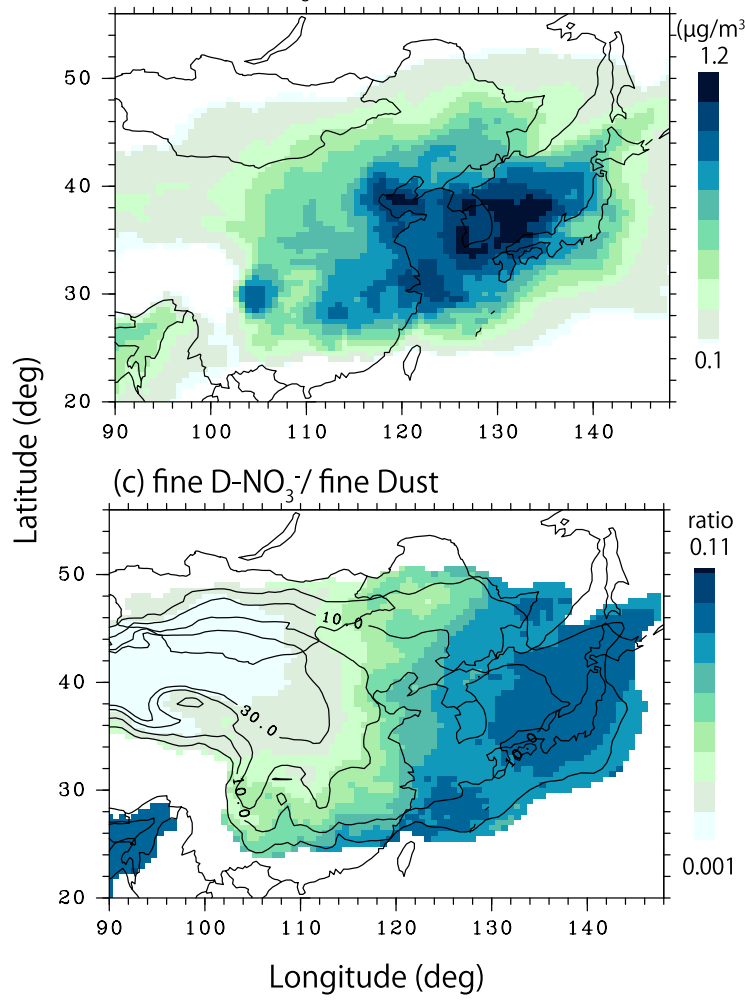

(b) coarse D- $\mathrm{NO}_{3}$

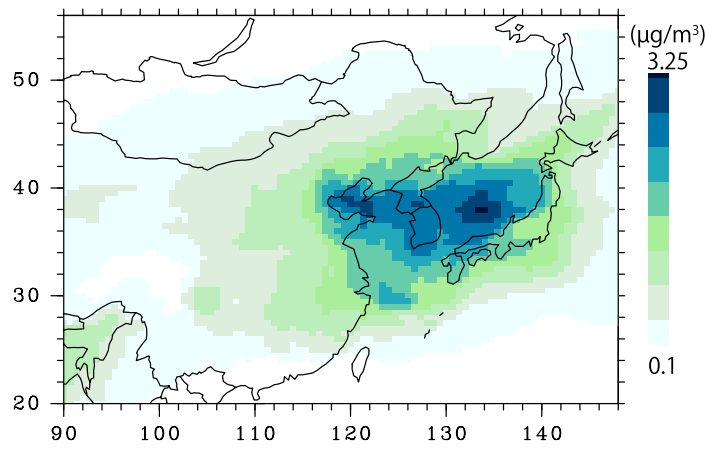

(d) coarse $\mathrm{D}-\mathrm{NO}_{3}-1$ coarse Dust

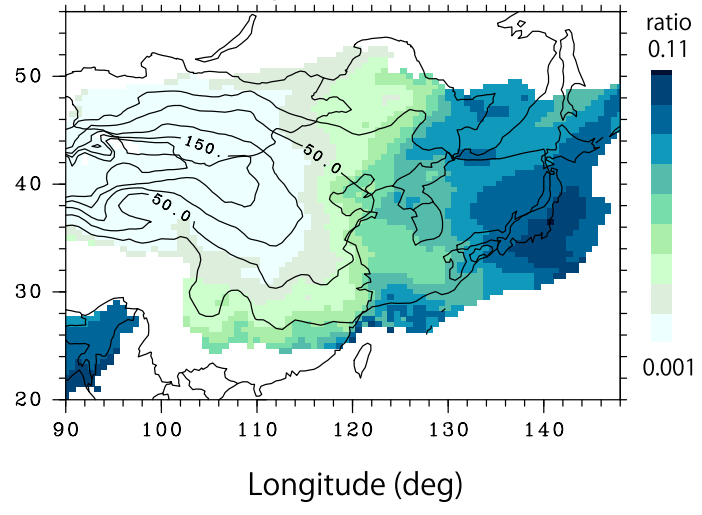

Fig. 6. Period average (a) fine and (b) coarse D- $\mathrm{NO}_{3}{ }^{-}$concentrations. (c) Fine and (d) coarse dust concentrations, indicated by lines, and the ratio of fine D- $\mathrm{NO}_{3}{ }^{-} /$dust concentration indicated by colors. Modeled first vertical level concentrations were averaged from 20 May and 5 June 2014. 


\section{Conclusions}

Two heavy dust storms that occurred in 24 May (Dust A) and 26 May (Dust B), 2014 in Mongolia and Inner Mongolia, China triggered long-lasting dust episodes observed from 26 May to 2 June 2014 in Fukuoka, Japan. During this period, dust and anthropogenic pollutants were transported simultaneously to Fukuoka and Korea, and stayed there for almost 8 days. We observed high time resolution (1-hour interval) fine- and coarse-mode aerosol concentrations during this long-lasting dust episode in Fukuoka. A CTM with the dust acid uptake processes reproduced the observed dust and fine/coarse aerosol time variations. The conclusions of our study are summarized below:

1) We clearly showed that both fine and coarse $\mathrm{NO}_{3}{ }^{-}$concentrations were strongly correlated with dust concentrations (e.g., $\mathrm{PM}_{\mathrm{c}}$ ). The observed ratio of fine to coarse $\mathrm{NO}_{3}{ }^{-}$concentrations was $1: 3$, and coarse $\mathrm{NO}_{3}^{-} / \mathrm{PM}_{\mathrm{c}}$ ranged from $5-8 \%,(\mathrm{r}=0.89)$. The CTM results showed that $\mathrm{HNO}_{3}$ gas was absorbed by dust particles (forming dust-nitrate) and transported toward Japan.

2) The CTM analysis showed that the coarse-mode dust-nitrate fraction was larger than the fine-mode dust-nitrate fraction. We confirmed that fine-mode dust-nitrate also played an important role in the observed fine $\mathrm{NO}_{3}^{-}$, and is important for $\mathrm{PM}_{2.5}$ air pollution.

3) Aerosol acidity observations confirmed that the dust aerosols neutralized the anthropogenic acid aerosols (e.g., nitrate and sulfate), and this neutralization was more effective for coarse dust particles.

4) The model sensitivity analysis showed that less than $5 \%$ of the coarse $\mathrm{D}-\mathrm{NO}_{3}{ }^{-}$originated from $\mathrm{NO}_{\mathrm{x}}$ emissions from Japan, and large amounts of $\mathrm{D}-\mathrm{NO}_{3}{ }^{-}$originated outside of Japan.

\section{Acknowledgments}

This work was supported by the Ministry of Education, Culture, Sports, Science and Technology (MEXT) and the Japan Society for the Promotion of Science (JSPS) Grants-in-Aid for Scientific Research (KAKENHI) program (grants JP25220101 and JP16H02946). The authors thank Dr. D. Fairlie of NASA for providing the dust-acid uptake version of GEOS-Chem, and Dr. S.S. Lee of the Korea Meteorological Administration for providing the PM observation data from Korea.

Edited by: T. Yasunari

\section{Supplements}

Supplement 1: Daily changes in the horizontal distribution of modeled dust and $\mathrm{SO}_{4}{ }^{2-}$ fields.

Supplement 2: Snapshot of particle volume concentration as a function of the particle diameter and depolarization ratio for POPC measurement.

Supplement 3: Horizontal distribution of $\mathrm{HNO}_{3}$ gas absorbed by dust.

\section{References}

Bey, I., J. Jacob, R. M. Yantosca, A. Logan, B. D. Field, A. M. Fiore, Q. Li, H. Y. Liu, J. Mickley, and M. G. Schultz, 2001: Global modeling of tropospheric chemistry with assimilated meteorology: Model description and evaluation. J. Geophys. Res., 106, 73-95.

Fairlie, T. D., D. J. Jacob, and R. J. Park, 2007: The impact of transpacific transport of mineral dust in the United States. Atmos. Environ., 41, 1251-1266.

Fairlie, T. D., D. J. Jacob, J. E. Dibb, B. Alexander, M. A. Avery, A. van Donkelaar, and L. Zhang, 2010: Impact of mineral dust on nitrate, sulfate, and ozone in transpacific Asian pollution plumes. Atmos. Chem. Phys., 10, 3999-4012.

Itahashi, S., I. Uno, K. Osada, Y. Kamiguchi, S. Yamamoto, K. Tamura, Z. Wang, Y. Kurosaki, and Y. Kanaya, 2017: Nitrate transboundary heavy pollution over East Asia in winter. Atmos. Chem. Phys., 17, 3823-3843, doi:10.5194/acp-2016879.

Kimoto, H., A. Ueda, K. Tsujimoto, Y. Mitani, Y. Toyasaki, and T. Kimoto, 2013: Development of continuous dichotomous aerosol chemical speciation analyzer. Clean Technol., 23, 49-52 (in Japanese).

Mahowald, N. M., and co-authors, 2010: Observed 20th century desert dust variability: impact on climate and biogeochemistry. Atmos. Chem. Phys., 10, 10875-10893.

Pan, X., I. Uno, Y. Hara, K. Kuribayasi, H. Kobayashi, N. Sugimoto, S. Yamamoto, T. Shimohara, and Z. Wang, 2015: Observation of the simultaneous transport of Asian mineral dust aerosols with anthropogenic pollutants using a polarization optical particle counter (POPC) during a long-lasting dust event in late spring 2014. Geophys. Res. Lett., 42, doi:10.1002/2014GL062491.

Perez, L., and co-authors, 2008: Coarse particles from Saharan dust and daily mortality. Epidemiology, 19, 800-807.

Uno, I., K. Osada, K. Yumimoto, S. Itahashi, S. Kuwahara, X. Pan, Y. Hara, and S. Yamamoto, 2016: Numerical analysis of trans-boundary transport of dust-nitrate during the longlasting yellow sand episode observed over the Northern Kyushu area in late May - early June 2014. J. Atmos. Environ. Soc. Japan, 51, 181-189 (in Japanese).

Uno, I., K. Yumimoto, X. L. Pan, Z. Wang, K. Osada, S. Itahashi, and S. Yamamoto, 2017a: Simultaneous dust-pollutants transport over East Asia: The tripartite environment ministers meeting March 2014 case study. SOLA, 13, 47-52, doi:10.2151/sola.2017-009.

Uno, I., K. Osada, K. Yumimoto, Z. Wang, S. Itahashi, X. Pan, Y. Hara, S. Yamamoto, and T. Nishizawa, 2017b: Importance of long-range nitrate transport based on long-term observation and modeling of dust and pollutants over East Asia. Aerosol and Air Quality Research, 17, doi:10.4209/aaqr. 2016.11.0494.

Yumimoto, K., I. Uno, X. Pan, T. Nishizawa, and S.-W. Kim, 2017: Inverse modeling of Asian dust emission with POPC observations for TEMM DSS 2014 case study. SOLA, 13, 31-35, doi:10.2151/sola.2017- 006.

Manuscript received 13 March 2017, accepted 9 May 2017

SOLA: https://www.jstage.jst.go.jp/browse/solal 